\title{
UPAYA MENINGKATKAN KEMAMPUAN BERPIKIR KREATIF SISWA MELALUI PENDEKATAN OPEN ENDED MATERI TRIGONOMETRI
}

\author{
Neni Maryani ${ }^{1}$, Nani Marlina ${ }^{2}$, Risma $_{\text {Amelia }}{ }^{3}$ \\ 1,2,3 IKIP SILIWANGI, Jl. Jendral Sudirman, Cimahi 40526 \\ Nenimaryani266@gmail.com
}

\begin{abstract}
This study aims to determine the increase in creative thinking skills of Vocational students through open ended learning. The method used is qualitative and this type of research is class action. The population of all students in one of the private vocational schools in the city of Cimahi while the sample was class X RPL B which amounted to 30 students. Data was collected based on observations, notes in the field, instruments in the form of tests of creative thinking ability with a number of 4 items with indicators (1) fluency, (2) flexibility, (3) authenticity, (4) detail / elaboration. The results of this study indicate that all the criteria for mathematical creative thinking have a significant increase through open ended learning with an increase in indicators (1) smoothness increased from $35 \%$ to $66.5 \%$. (2) flexibility increases from $25.5 \%$ to $60.6 \%$. (3) authenticity increased from $40.2 \%$ to $64.8 \%$. (4) details / elaboration increased from $30 \%$ to $55.5 \%$
\end{abstract}

Keywords: creative, open ended thinking skills

\begin{abstract}
Abstrak
Penelitian ini bertujuan untuk mengetahui peningkatan kemampuan berpikir kreatif siswa SMK melalui pembelajaran open ended. Metode yang digunakan yaitu kualitatif dan jenis penelitian ini merupakan tindakan kelas. Populasi semua siswa di salah satu sekolah SMKswasta di Kota Cimahi sedangkan sampelnya kelas X RPL B yang berjumlah 30 siswa. Data dikumpulkan berdasarkan observasi, catatan di lapangan, instrumen berupa tes kemampuan berpikir kreatif dengan jumlah 4 butir soal dengan indikator (1) kelancaran, (2) kelenteruran, (3) keaslian, (4) keterincian/elaborasi. Hasil penelitian ini menunjukan bahwa semua kriteria kemampuan berpikir kreatif matematik mengalami peningkatan yang signifikan melalui pembelajaran open ended dengan peningkatan pada indikator (1) kelancaran meningkat dari 35\% menjadi 66,5\%. (2) kelenturan meningkat dari $25,5 \%$ menjadi $60,6 \%$. (3) keaslian meningkat dari $40,2 \%$ menjadi $64,8 \%$. (4) keterincian/elaborasi meningkat dari $30 \%$ menjadi $55,5 \%$
\end{abstract}

Kata kunci: kemampuan berpikir kreatif, open ended

Agar tercapainya kemampuan siswa yang kreatif, innovatif dan berwawasan luas terutama pada bidang matematika diperlukan suatu cara pengajaran yang efektif diterapkan oleh guru. Sependapat (Syaban 2006) bahwa diperlukannya beberapa kecakapan guru untuk memilih sebuah model pembelajaran dengan tepat, baik untuk materi ataupun keadaaan pembelajaran.Mengingat matematika disebut ilmu deduktif sebagai dasar awal iptek serta mengembangkan pola pikir dan analisa siswa. Maka dari itu kemampuan berpikir kreatif sangat diperlukan dalam proses pembelajaran. Menurut Lutfi (2016) Proses berpikir kreatif merupakan proses yang digunakan ketika seseorang memunculkan suatu ide baru, mensintesis ide-ide tersebut serta mengimplementasikannya, menurut Zulfah (2017) berpikir termasuk aktivitas kognitif tingkat tinggi yang bermanfaat bagi siswa untuk dapat membandingkan atau membedakan sesuatu, merumuskan dan menyelesaikan suatu permasalah, dapat mengeluarkan ide-ide, serta mampu membuat keputusan dalam suatu masalah. Menurut Apriansyah, Ramdani (2018) kemampuan berpikir kreatif adalah aktivitas berpikir seorang individu 
untuk memperoleh gagasan baru atau cara baru dalam upaya menyelesaikan permasalahan dan menghasilkan bermacam-macam kemungkinan jawaban.

Berdasarkan pengalaman mengajar peneliti (Gulo 2016) di SMAN 1 Blangkejeren bahwa pembelajaran matematika, siswa tergolong pasif, karena lebih tergantung pada pengajaran satu arahdari pengajar. Rendahnya partisipasi siswa saat pembelajaran, mengakibatkan menurunnya nilai. Terutama trigonometri sebab siswa harus memahami rumus-rumusnya. strategi yang memungkinkan meningkatkannya ketercapaian kompetensi adalah penggunaan pendekatan yang selaras, untuk mendorong daya berpikir siswa yang lebih aktif, kreatif dan mempunyai berbagai penyelesaian yaitu open ended (suatu pembelajaran yang menuntut siswa memacu pemikiran kreatif dan bervariasi dalam menjawab suatu masalah) sejalan dengan (Anwar, Johar \& Juandi2015) pendekatan open ended suatu proses pengkajian yang dimulai dengan pemberian masalah terbuka kepada siswa serta beragam penyelesaian. Berikut beberapa penelitian yang pernah dilakukan oleh beberapa peneliti, menurut Rustyani, Komalsari, Bernard dan Akbar (2018) bahwa penggunaan pendekatan open ended dalam pembelajaran matematika dapat meningkatkan sikap disposisi matematis siswa kelas X RPL B. Menurut Rahayu, Akbar, Afrilianto (2018) bahwa pencapaian kemampuan berpikir kreatif matematik siswa yang menggunakan metode Mind Mappingn melalui strategi Thinking Aloud Pair Problem Solving (TAPPS) lebih baik dari padayang menggunakan pembelajaran biasa. Menurut Saironi, Sukestiyarno (2017) Kemampuan Berpikir Kreatif Matematis (KBKM) siswa dan pembentukan karakter rasa ingin tahu siswa merupakan salah satu aspek penting dalam pembelajaran matematika dan Pembelajaran Open Ended (OEL) berbasisetnomatematika, salah satu model pembelajaran yang dapat diterapkan untuk meningkatkan KBKM siswa dan pembentukan Karakter Rasa Ingin Tahu (KRIT) siswa. Sehingga peneliti melakukan penelitian untuk mengetahui peningkatan kemampuan berpikir kreatif dengan open ended pada materi trigonometri.Untuk mengetahui tingkat kemampuan yang dimiliki, menggunakan acuan yang dikemukakan Sumarmo (2016) 1) kelancaran, 2) kelenturan, 3) keaslian/originalitas, 4) keterincian/elaborasi sebagai berikut

\section{Tabel 1.}

Indikator Kemampuan Berpikir Kreatif Menurut Sumarmo (2016)

\begin{tabular}{|l|l|}
\hline Indikator Berpikir Kreatif & Jawaban \\
\hline Kelancaran & Mencetuskan banyak ide,jawaban,pertanyaan dengan lancar \\
\hline Kelenturan & $\begin{array}{l}\text { Menghasilkan pendapat, hasil dan pertanyaan, yang beraneka } \\
\text { ragam, terlihat dari permasalahan yang diberikan, bisa } \\
\text { merubah cara pemikiran, }\end{array}$ \\
\hline Keaslian & $\begin{array}{l}\text { Mampu mengemukakan ungkapan unik, tidak biasa dan } \\
\text { mampu membuat kombinasi-kombinasi yng tidak lazim, }\end{array}$ \\
\hline Keterincian/Elaborasi & $\begin{array}{l}\text { Mampu memperjelas gagasan, menguraikan detail-detail } \\
\text { menjadi sebuah gagasan jelas. }\end{array}$ \\
\hline
\end{tabular}

Dengan demikian maksud riset ini untuk mengetahui peningkatan kemampuan berpikir kreatif siswa SMK melalui pembelajaran open ended 


\section{METODE PENELITIAN}

Peneliti menggunakan tindakan kelas dan mengumpulkan data dengan bantuan soal tes instrumen dengan kemampuan berpikir kreatif. Populasi semua siswa kelas X disalah satu SMK swata di Kota Cimahi sedangkan sampelnya yaitu kelas X RPL-B. Data dikumpulkan berdasarkan observasi, catatan di lapangan, instrumen berupa tes awal yang berperan sebagai evaluasi awal.Penelitian perlakuan dikelas di mulai dari permasalahan real yang hadapi guru ketika proses belajar mengajar, kemudian di refleksikan. Alternatif solusi harus ada, sehingga dilakukan tindakan-tindakan nyata yang tersusun. Tahapan yang digunakan (1) tahap merencanakan, (2) tahap melaksanakan, (3) refleksi dan evaluasi. Pada tahap perencanaan melakukan identifikasi masalah serta penyebabnya, di sertai dengan solusi masalah tesebut yaitu pembelajaran open ended. Pada tahap refleki dijalankan untuk mengkaji tingkat kesuksesan ketika di laksanakannya tindakan kelas. Pada tahap evaluasi di lakukan untuk mengetahi tingkat ketercapaian.

\section{HASIL DAN PEMBAHASAN}

Kondisi tes awal menunjukan yakni kemampuan berpikir kreatif matematik siswa SMK kelas X RPL-B yang berjumlah 30 orang siswa, yaitu indikator (1) kelancaran sebanyak 7 orang siswa atau $20 \%$, (2) kelenturan berjumlah 3 siswa dengan presentase $8,3 \%$,(3) keaslian hanya 6 orang siswa atau $19,4 \%$ dan (4) Keterincian / elaboarsi yaitu 5 orang siswa 16,6\%. Hal tersebut disebabkan kurang kreatifnya siswa dalam mengisi soal hanya terpaku pada contoh-contoh yang diberikan.

Pelaksanaan siklus satu yang memuat dua pertemuan. Pada hasil refleksi dan evaluasi peneliti mengambil kesimpulan adanya peningkatan walaupun tidak terlalu baik. Keberhasilan yang tercapai pada kegiatan siklus I yaitu siswa sudah bisa mencetuskan banyak ide-ide mengatasi kesulitan baik secara kelompok ataupun individu dan siswa banyak bertanya. Akan tetapi ditemukannya perbedaan ketuntasan yang belum tercapai yaitu nilai yang belum mencukupi kriteria. hal tersebut disebabkan karena siswa sekedar cakap menyampaikan gagasannya saja tanpa memprihatikan konsep sebenarnya, pada saat diskusi kelompok hanya mengandalkan teman yang berprestasi di kelompoknya, kurang menghargai teman kelas atau kelompok yang presentasi.Dilihat dari lembar jawaban lks siswa kebanyakan siswa menjawab atau menyelesaikan dengan cara yang sama padahal soal - soal pada LKS dapat di selesaikan dengan penyelesaian yang berbeda.

Faktor penyebab siswa belum terbiasa menyelesaikan soal yang memiliki banyak jawaban, guru kurang tegasdikelas, guru kurang dapat mengkoordinir kelas, kurangnya reward untuk memotivasi siswa. Alternative tindakan lanjut untuk siklus II guru memberikan beberapa pertanyaan yang memiliki banyak cara dan jawaban, guru bertindak tegas terhadap siswa yang tidak memperhatikan, memberikan apresiasi berupa reward kepada siswa yang mendapatkan nilai tinggi dari hasil diskusi kelompok serta siswa yang aktif bertanya. Berdasarkan pengamatan hasil siklus I pada indikator (1) kelancaran dalam berpikir kreatif sebanyak 11 siswa atau 35\%, (2) kelenturan dengan menghasilkan banyak ide-ide tanpa konsep sebenarnya sebanyak 8 orang atau 25,5\%,(3) keaslian mampu 
mengemukakan pendapat baru 40,2\% yaitu sebanyak 12 orang,(4) keterincian / elaborasi memperoleh dengan rinci tanpa penyelesain yang tepat sejumlah 9 siswa presentase $30 \%$.

Untuk megevaluasi pada siklus I dilakukan siklus II. Pelaksanaan siklus II terdiri dari 2 pertemuan, hasil dari siklus II yaitu indikator bepikir kreatif (1) kelancaran mencetusakan banyak ide dan jawaban 66,5\% dengan siswa 20 ,(2)kelenturan menghasilkan banyak ide-ide tanpa konsep sebenarnya yaitu 25,5\%, dengan8 orang,(3) keaslian dengan mampu mengemukakan pendapat baru yaitu 12 orang dengan 40,2\%, (4) keterincian / elaborasi dapat mengembangkan ide dengan rinci tanpa penyelesain yang tepat sebesar 30\% sebanyak 9 orang. Indikator kemampuan berpikir kreatif siswa telah terjadi peningkatan pada tiap indikator maka peneliti tidak perlu melakukan siklus selanjutnya. Hasil Pengamatan Mengenai Berpikir Kreatif Melalui Open ended disediakan Pada Tabel 2 berikut

Tabel 2.

Hasil Pengamatan Kemampuan Berpikir Kreatif Melalui Open ended

\begin{tabular}{|l|l|l|l|}
\hline Indikator & Tes Awal & Siklus I & Siklus II \\
\hline Kelancaran & $20 \%$ & $35 \%$ & $66,5 \%$ \\
& $(7$ orang siswa) & $(11$ orang) & $(20$ orang $)$ \\
\hline Kelenturan & $8,3 \%$ & $25,5 \%$ & $60,6 \%$ \\
& $(3$ orang siswa) & (8 orang) & $(19$ orang) \\
\hline Keaslian & $19,4 \%$ & $40,2 \%$ & $64,8 \%$ \\
& $(6$ orang siswa) & $(12$ orang) & $(20$ orang) \\
\hline Keterincian / elaboarsi & $16,6 \%$ & $30 \%$ & $55,5 \%$ \\
& $(5$ orang siswa) & (9orang) & $(17$ orang) \\
\hline
\end{tabular}

Kemampuan berpikir kreatif siswa sebelum tindakan masih kurang, hal ini dapat dilihat dari siswa yang dapat menjawab soal-soal instrument namun setelah diberikan treatment dengan pembelajaran open ended mulai mengalami peningkatan. Pada indikator kelancaran mulai terlihat dari jawaban siswa bervariasi, kelenturan mulai mengalami peningkatan dengan jawaban siswa yang selaras dengan berpikir siswa, keaslian siswa sudah dapat mengemukakan pendapat yang baru sesuai dengan wawasan yang dimiliki dilihat dari jawaban instrument siswa, keterincian/elaborasi yaitu pernyataan yang didukung berdasarkan penyelesaian yang tepat. Pemberian berbagai contoh bentuk soal-soal terbuka yang dapat mempermudah menyelesaikan masalah terbuka tanpa mencontek kepada teman.

Berikut contoh soal terbuka yang memilki jawaban benar oleh siswa kelas $\mathrm{X}$

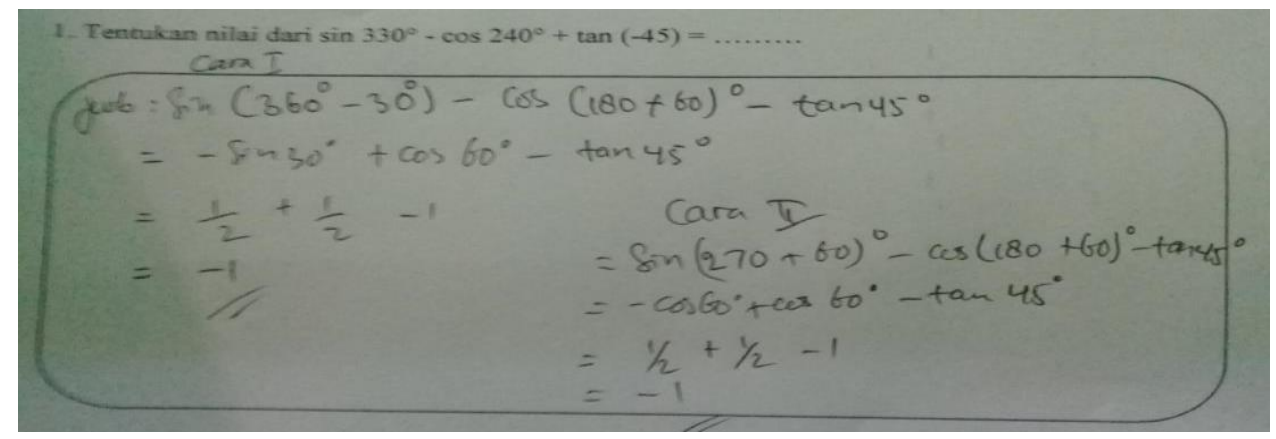

Gambar 1. Cuplikan Jawaban Siswa pada Soal Nomor 1 
Contoh soal yang banyak siswa menjawab salah

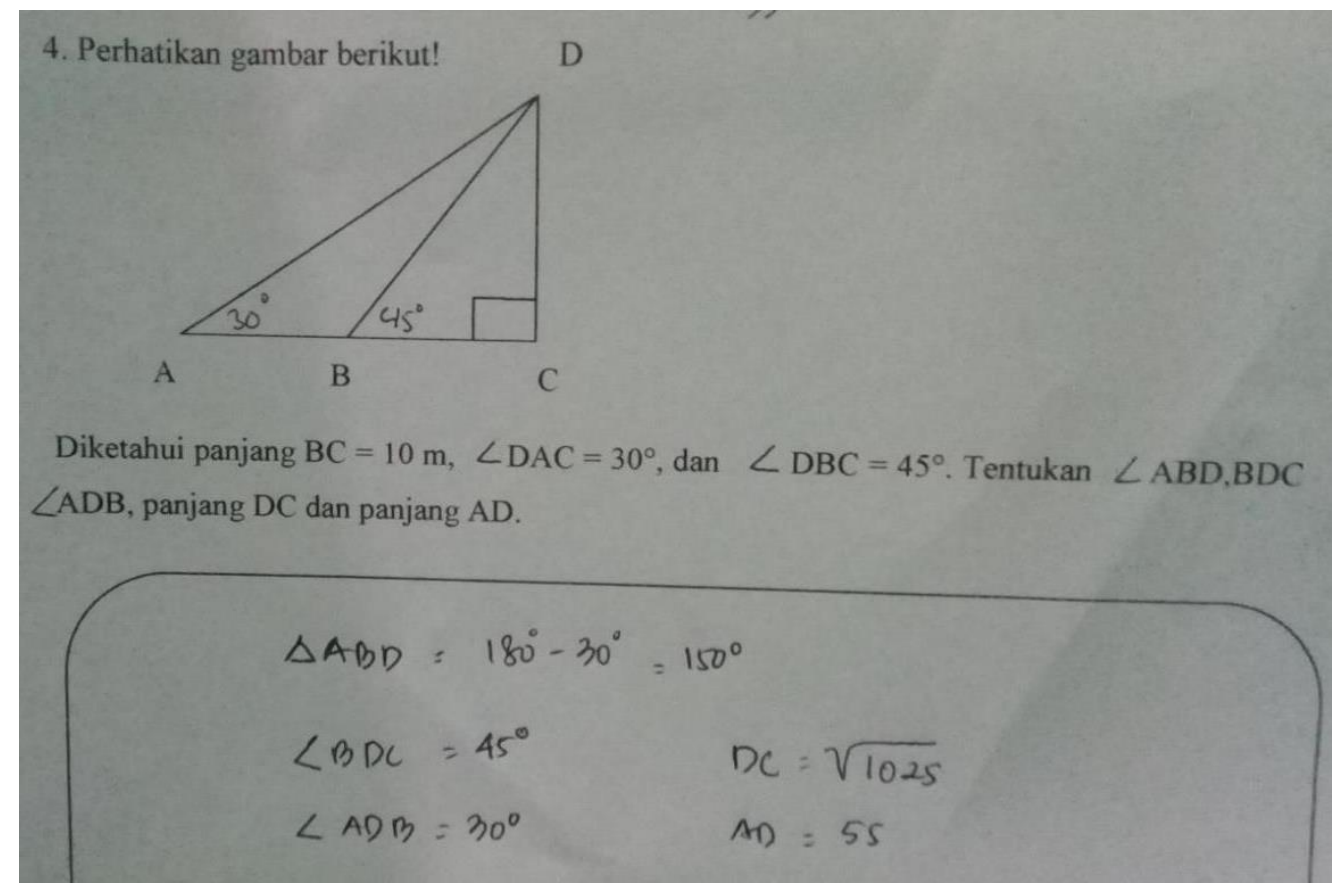

Gambar 2. Cuplikan Jawaban Siswa yang Menjawab Salah

Kemampuan berpikir kreatif sebelum dilakukan tindakan masih rendah, namun setelah dilakukan tindakan siklus II mengalami peningkatan hingga mencapai indikator pencapaian, hal ini didukung oleh hasil penelitian (Lambertus, Arapu dan Patih 2013) yang menyimpulkan bahwa penerapan open ended dapat meningkatkan kemampuan berpikir kreatif siswa yang mempunyai progres sebesar 0,56 dengan klasifikasi sedang.

\section{KESIMPULAN}

Berdasarkan analisis data penelitian merangkum bahwa kemampuan berpikir kreatif dapat meningkat dengan pembelajaran open ended.Hal tersebut dapat ditinjau dari persentase indikatorindikator yang diamati dari siklus 1 ke siklus 2 yaitu (1) kelancaran meningkat dari $35 \%$ menjadi $66,5 \%$. (2) kelenturan meningkat dari $25,5 \%$ menjadi $60,6 \%$. (3) keaslian meningkat dari 40,2\% menjadi $64,8 \%$. (4) keterincian/elaborasi meningkat dari $30 \%$ menjadi 55,5\%

Saran bagi guru matematika 1) pengajar bisa menggunakan pembelajaranopen ended agar siswa dapat berpikir kreatif, 2)memberikan berbagai bentuk contoh soal-soal terbuka dan pemahaman berpikir siswa, 3)memperhatikan siswa yang malas belajar. 
Saran bagi siswa 1) bekerjasama dalam diskusi kelompok, 2) hendaknya siswa berbagi pengetahuan dengan teman lain, 3) mencari tambahan referensi pengetahuan pada materi yang dipelajari.

\section{DAFTAR PUSTAKA}

Anwar, N., Johar, R., \& Juandi, D. (2015). Pengembangan Perangkat Pembelajaran Berbasis Pendekatan Open-Ended untuk Meningkatkan Kemampuan Berpikir Kreatif matematik Siswa SMP. Jurnal Didaktik Matematika, 2(1).

Gulo, A. (2016). Upaya meningkatkan hasil belajar matematika dengan materi trigonometri melalui penerapan model pembelajaran soal terbuka (open ended) di kelas x-2 sma negeri 1 blangkejeren. Jurnal media inovasi edukasi (jmie), 2(2), 110-119.

Lambertus, L. A., \& Patih, T. (2013). Penerapan Pendekatan Open-Ended untuk Meningkatkan Kemampuan Berpikir Kreatif Matematik Siswa SMP. Jurnal Pendidikan Matematika, 4(1), 73-82.

Purnomo, A., \& Sujadi, a. A. (2014). Upaya meningkatkan kemampuan berpikir kreatif dan prestasi belajar matematika siswa kelas $\mathrm{x}$ teknik computer jaringan (tkj) smk negeri 3 yogyakarta dengan model pembelajaran problem posing secara berkelompok. Union: Jurnal ilmiah pendidikan matematika, 2(2).

Retnowati, D., \& Budi, M. (2013). Upaya Meningkatkan Pemahaman Konsep dan Disposisi Matematis Menggunakan Model Pembelajaran Treffinger.

Ramdani, M., \& Apriansyah, D. (2018). Analisis Kemampuan Pemahaman dan Berfikir Kreatif Matematik Siswa Mts pada Materi Bangun Ruang Sisi Datar. Jurnal Cendekia: Jurnal Pendidikan Matematika, 2(2), 1-7.

Sumarmo, U. (2016). Pedoman Pemberian Skor pada Beragam Tes Kemampuan Matematik. Kelengkapan Bahan Ajar Mata Kuliah Evaluasi Pembelajaran Matematika pada Program Magister Pendidikan Matematika STKIP Siliwangi: Tidak diterbitkan.

Syaban, M. (2006). Menggunakan open-ended untuk memotivasi Berpikir Matematika. Educare, 2(2). Saironi, M., \& Sukestiyarno, Y. L. (2017). Kemampuan Berpikir Kreatif Matematis Siswa dan Pembentukan Karakter Rasa ingin Tahu Siswa pada Pembelajaran Open Ended Berbasis Etnomatematika. Unnes Journal of Mathematics Education Research, 6(1), $76-88$

Rustyani, N., Komalasari, Y., Bernard, M., \& Akbar, P. (2018). UPAYA MENINGKATKAN DISPOSISI DENGAN PENDEKATAN OPEN ENDED PADA SISWA SMK KELAS X-RPL B. Journal on Education, 1(2), 265-270. 
UPAYA MENINGKATKAN KEMAMPUAN BERPIKIR KREATIF SISWA MELALUI PENDEKATAN OPEN ENDED

MATERI TRIGONOMETRI, Neni Maryani, Nani Marlina,Risma Amelia

Dewi, I. N., Akbar, P., \& Afrilianto, M. (2018). KEMAMPUAN BERPIKIR KREATIF MATEMATIS DAN DISPOSISI MATEMATIS SISWA SMP MELALUI PENDEKATAN KONTEKSTUAL. Journal on Education, 1(2), 279-287.

Lutfi, A. (2016, November). Problem Posing dan Berpikir Kreatif. In Prosiding Seminar Nasional Matematika dan Pendidikan Matematika.

Zulfah, Z. (2017). Pengaruh Penerapan Model Pembelajaran Kooperatif Tipe Think Pair Share Dengan Pendekatan Heuristik Terhadap Kemampuan Pemecahan Masalah Matematis Siswa Mts Negeri Naumbai Kecamatan Kampar. Jurnal Cendekia: Jurnal Pendidikan Matematika, 1(2), 1-12. 